\title{
Effect of image radiometric correction levels of Landsat images to the land cover maps resulted from maximum likelihood classification
}

\author{
Muhammad Kamal ${ }^{*}$, Faaris H. Muhammad ${ }^{1}$, and Shifa A. Mahardhika ${ }^{1}$ \\ ${ }^{1}$ Department of Geographic Information Science, Faculty of Geography, Universitas Gadjah Mada, \\ Yogyakarta, Indonesia
}

\begin{abstract}
Radiometric correction of remote sensing images is required to improve the quality of image pixel values and provide a measurable physical unit of each pixel. Selection of the appropriate image radiometric and atmospheric correction level defines the success of any remote sensing-based mapping applications. This study aims to assess the effects of radiometric correction levels applied to Landsat 8 (Operational Land Imager, OLI) image acquired in 2018 to the results of the land cover classification using the Maximum Likelihood Classifier (MLC). The image was corrected into four levels of radiometric and atmospheric correction; no correction (digital number), at-sensor radiance, at-sensor reflectance (top of atmosphere, ToA), and at-surface reflectance (bottom of atmosphere, BoA). A set of classification training sample covering five land cover classes (mangroves, inland vegetation, exposed soil, built-up area, and water body) was selected from the image. To ensure fair class comparison, the number of training sample were set to be proportional to the area of targeted classes. The results of this study show that there is no difference in the classification results of each level of correction, both in the area and distribution of the classes. This finding indicates that MLC result is invariable of image correction level.
\end{abstract}

\section{Introduction}

Providing updated land cover maps is essential in any monitoring activities, including in mangrove ecosystems. Currently mangrove ecosystems are increasingly threatened by land conversions, reclamations and natural disturbances such as tsunamis, storms and sea level rise [1]. Human activities that convert mangrove land for settlement, aquaculture, industrial activities and infrastructure development are very detrimental to the sustainability of mangrove ecosystems. From natural aspect, the impact of rising sea levels changes the zonation of mangrove areas based on their association with the land, which occurs because there are certain types of mangroves that cannot survive high salinity conditions and are always flooded which ultimately results in mangrove mortality [2]. According to Giri et al. [3], remote sensing in this case plays a role in helping to identify changes in mangrove

\footnotetext{
*Corresponding author: m.kamal@ugm.ac.id
} 
cover over time through multi-temporal image recording capabilities. The identification results can be used as a basis for multi-temporal and change detection in mangrove cover.

Multi-temporal monitoring of mangrove cover is an important step in supporting efforts to restore and plan mangrove ecosystems. Monitoring results can be used to identify the growth rate or shrinkage of mangrove areas and can be used as a basis for evaluating changes that occur. Prior to performing mangrove status monitoring, a series of land cover maps are required as basis for monitoring or change detection analysis [4]. These maps could be produced from many mapping algorithms available. However, up to know, the most popular and easily adopted classification method is by using Maximum Likelihood Classifier (MLC, [5]). This classification algorithm works based on the set of land cover sample or training area provided, and the algorithm calculates the likelihood of a pixel become member of a land cover class. Higher likelihood of a pixel to certain land cover sample class will determine the class membership of that pixel. However, the question remains is whether we need to perform radiometric correction of the remote sensing image or not in order to apply MLC [6]. Therefore, it is necessary to conduct research that applies these image corrections and examine the classification result from different levels of image correction.

Mangroves in the Perancak estuary have experienced significant changes since forest opening for ponds in the 80s [7]. Over time, various efforts have been made to restore the mangrove area by replanting mangrove vegetation. According to reports from several researchers [8,9] the mangrove restoration effort succeeded in returning most of the fishponds to mangroves. Multi-temporal remote sensing imagery can help monitor mangrove change. Remote sensing imagery provides an efficient tool for this purpose because it covers large areas and the image data can be obtained at different time of acquisitions. The utilization of remote sensing images for land cover change studies has been done a lot, both at small and large scale, and with various degree of success. This study aims to assess the effects of radiometric correction levels applied to Landsat 8 OLI image acquired in 2018 to the results of their land cover classification using MLC.

\section{Methods}

\subsection{Study site}

The study site for this study was in the south part of Negara District, Jembrana Regency, Bali Province, where there is a patch of mangrove forest at Perancak Estuary. This location was chosen because of the variation of land cover conditions throughout the year of observations, it has clear boundaries between land cover classes, and easily accessible. Perancak Estuary is one of the mangrove forests in Bali which is areas located at $114^{\circ} 37^{\prime} 11.7^{\prime \prime}-114^{\circ} 37^{\prime} 12.2^{\prime \prime} \mathrm{E}$ and $08^{\circ} 24^{\prime} 33.5^{\prime \prime}-08^{\circ} 24^{\prime} 36.1^{\prime \prime} \mathrm{S}$ (Fig. 1). It has an area of about 876 ha with more than 390 ha of both productive and abandoned fishponds, and 78.6 ha of mangrove forests [10].

There are five major land cover classes found in this study area; mangroves, inland vegetation, built-up areas, bare land, and water body. All of these land cover classes are the targeted classification objects in this study. The capital city of Jembrana Regency - Negara - which is located in the northern part of the study site, consists of mainly built-up objects. Fishponds with blue colour in Fig. 1 found along the rivers and spread in the middle of the study site. The mangrove forest in the Perancak Estuary is the remaining forest area after being converted into a pond area around 1980 [7]. The mangrove forest of Perancak is divided into natural and rehabilitated mangroves. There are nine mangrove species in this 
area with the Sonneratia alba is the most dominant species. Mangrove objects represented in dark orange colour in the image (Fig. 1).

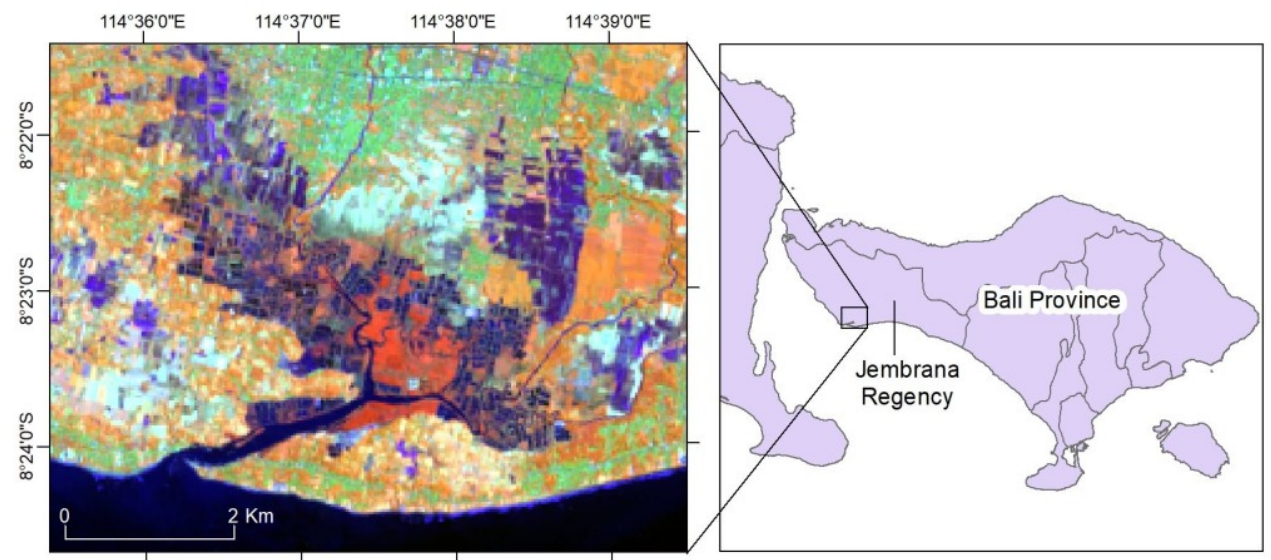

Fig. 1. Landsat 8 OLI (RGB 563) of the research site in part of Jembrana Regency, Bali.

\subsection{Image dataset}

The remote sensing image utilized in this study was Landsat 8 OLI covering part of Jembrana Regency Bali (path 117 row 66), acquired on 14 April 2018. This image has pixel size of 30 meters and eleven bands, and freely available from Earth Explorer (https://earthexplorer.usgs.gov/). The image has been obtained at L1TP correction level or level-1 precision and terrain corrected product level. It means that the radiometric and geodetic property of the image have been corrected using reference datasets [11]. Because this study focuses on the thematic information derived from the image rather than the geometric aspect, additional geometric correction was not performed. In this study, we only focus on the six commonly used bands, that are blue $(450-510 \mathrm{~nm})$, green $(530-590 \mathrm{~nm})$, red (640-670 nm), near infrared (NIR, 850-880 nm), short wave infrared1 (SWIR1, 1570$1650 \mathrm{~nm}$ ), and short wave infrared2 (SWIR2, 2110-2290 nm) bands. All of the six bands were incorporated in the land cover image classification process.

\subsection{Radiometric and atmospheric image correction}

Radiometric correction was performed to convert the digital number of image pixels into a value with a specific physical unit. The process of converting the pixel value is based on the recording parameters obtained from the image header and radiometric correction guideline for Landsat 8 OLI. Radiometric correction in this study was carried out to convert the pixel digital numbers (DN) into the value of three physical units: (1) at-sensor radiance $\left(\mathrm{W} / \mathrm{m}^{2} \mathrm{sr}\right.$ $\mu \mathrm{m})$, (2) at-sensor reflectance (\%) or Top of Atmosphere (ToA), and (3) at-surface reflectance $(\%)$ or Bottom of Atmosphere (BoA). The first two conversions were performed by following the Conversion of DNs to Physical Units procedures mentioned in Chapter 5 of the Landsat 8 OLI handbook [11]. The third conversion was performed using Dark Object Subtraction (DOS) technique to compensate the atmospheric effect on each band. It works based on an assumption that reflectance from spectrally-dark objects on the image includes a substantial additive component of atmospheric scattering [12]. DOS searches for the darkest pixel value in each band on the image. The additive scattering is removed by subtracting this value from every pixel in the band. In this case, we used a dark pixel which 
has the lowest value in the NIR band as the reference for pixel value subtraction. These result values were used as a basis for image classification result comparison at a later stage.

\subsection{Land cover classification}

The classification algorithm utilized in this study is the maximum likelihood classification (MLC) which considers the statistical distribution of the sample pixel values. MLC assumes that the statistics for each targeted class in each band of the image are normally distributed. Then it calculates the probability of each pixel on the image to belongs to a specific targeted class. Each pixel is assigned to the targeted class that has the highest probability membership or the maximum likelihood. If the highest probability of pixel is smaller than a threshold specified, the pixel will remain unclassified [5]. A set of classification training sample covering five main land cover classes (mangroves, inland vegetation, exposed soil, built-up area, and water body) was selected from the image. In this case, we tried to use point training sample to ensure the high distribution and representativeness of the samples for each targeted land cover. The selection of training sample considers the field survey conducted on July 2019.

The algorithm was applied using the same training sample set to all image correction levels from previous process, including digital number, at-sensor radiance, at-sensorreflectance, and at-surface reflectance images. The land cover image classification resulted from different correction levels were then compared and contrasted by overlying each of the image to find out the effect of the correction levels to the land cover results. Since this study using a single image source, the geometric property between the land cover maps produced will not be an issue. A simple map to map comparison was used to identify the both land cover class and area differences between maps.

\section{Results and discussions}

\subsection{Radiometric image correction}

Radiometric correction of Landsat 8 OLI images was performed by referring to Landsat 8 Data Users Handbook [11]. The parameters used for the correction were obtained from the metadata of each image and the detailed parameters are presented in Table 1 as follow:

Table 1. Radiometric correction parameters of Landsat 8 OLI image.

\begin{tabular}{|c|c|c|c|c|}
\hline \multirow{2}{*}{ Band } & \multicolumn{2}{|c|}{ Radiance } & \multicolumn{2}{c|}{ Reflectance } \\
\cline { 2 - 5 } & Multiplicative & Additive & Multiplicative & Additive \\
\hline 2 & 0.012783 & -63.91334 & $2.0000 \mathrm{E}-05$ & -0.100000 \\
\hline 3 & 0.011779 & -58.89560 & $2.0000 \mathrm{E}-05$ & -0.100000 \\
\hline 4 & 0.0099328 & -49.66409 & $2.0000 \mathrm{E}-05$ & -0.100000 \\
\hline 5 & 0.0060784 & -30.39195 & $2.0000 \mathrm{E}-05$ & -0.100000 \\
\hline 6 & 0.0015116 & -7.55820 & $2.0000 \mathrm{E}-05$ & -0.100000 \\
\hline 7 & 0.00050950 & -2.54752 & $2.0000 \mathrm{E}-05$ & -0.100000 \\
\hline
\end{tabular}

The whole radiometric correction process was done using ENVI 4.7 image processing software through the math band function. An example of the application of the radiance level correction formula in this software is as follows: 
The results of this radiometric correction are images with spectral radiance values with physical units $\mathrm{W} / \mathrm{m}^{2} \mathrm{sr} \mu \mathrm{m}$. The next correction level, at-sensor (ToA) reflectance, was also processed using correction parameters from Table 1. To obtain the true ToA reflectance, additional correction for the solar elevation angle was performed in this conversion. The local sun elevation angle data is available in the image header. The last correction level, DOS, was aimed to compensate the effect of atmospheric attenuation in the image scene. The dark object was selected by considering the object reflectance characteristics in NIR band. Deep, clear and calm water was selected as a dark object reference in this process. In theory, NIR absorbs most of this feature thus provide minimum reflectance (near or equal to zero). Any reflectance more than 0 will be considered as additive effect from atmospheric attenuation and need to be corrected.

Statistical comparison of pixel values between four levels of image correction in the study area is presented in Table 2. Based on this table, we can see the progression of changes in each of the pixel value from unitless digital number to percent surface reflectance. The pixel value range for each correction level is completely different to the others. The biggest pixel value different were found between digital number and at-sensor radiance, and between at-sensor radiance and at-sensor reflectance. This big difference was attributed to the different physical units of each correction level. The minimum value in the at-surface reflectance was all set to zero. However, the maximum values obtained were slightly off compare to the theoretical reflectance maximum value ( 1 or $100 \%)$. To visually examine the pixel value changes resulted from these image correction levels, graphs of objects spectral reflectance is presented in Fig. 2.

Table 2. Statistical pixel values of images before and after radiometric/atmospheric correction.

\begin{tabular}{|c|c|c|c|c|c|c|}
\hline \multirow{2}{*}{ Band } & \multicolumn{3}{|c|}{ Digital Number } & \multicolumn{3}{c|}{ At-sensor radiance } \\
\cline { 2 - 7 } & Min & Max & Mean & Min & Max & Mean \\
\hline 2 & 0 & 52415 & 7051.34 & -63.91 & 606.10 & 26.22 \\
\hline 3 & 0 & 53859 & 6099.23 & -58.89 & 575.50 & 12.94 \\
\hline 4 & 0 & 57332 & 5526.80 & -49.66 & 519.80 & 5.23 \\
\hline 5 & 0 & 65535 & 7796.10 & -30.39 & 367.95 & 16.99 \\
\hline 6 & 0 & 65535 & 5971.38 & -7.55 & 91.50 & 1.46 \\
\hline 7 & 0 & 65535 & 5017.68 & -2.54 & 30.84 & 0.008 \\
\hline \multirow{2}{*}{ Band } & \multicolumn{2}{|c|}{ At-sensor reflectance } & \multicolumn{2}{|c|}{ At-surface reflectance } \\
\cline { 2 - 7 } & Min & Max & Mean & Min & Max & Mean \\
\hline 2 & -0.12 & 1.14 & 0.049 & 0 & 1.257 & 0.169 \\
\hline 3 & -0.12 & 1.17 & 0.026 & 0 & 1.292 & 0.146 \\
\hline 4 & -0.12 & 1.26 & 0.012 & 0 & 1.375 & 0.132 \\
\hline 5 & -0.12 & 1.45 & 0.067 & 0 & 1.572 & 0.187 \\
\hline 6 & -0.12 & 1.19 & -0.001 & 0 & 1.310 & 0.119 \\
\hline 7 & -0.12 & 1.19 & -0.019 & 0 & 1.310 & 0.1 \\
\hline
\end{tabular}




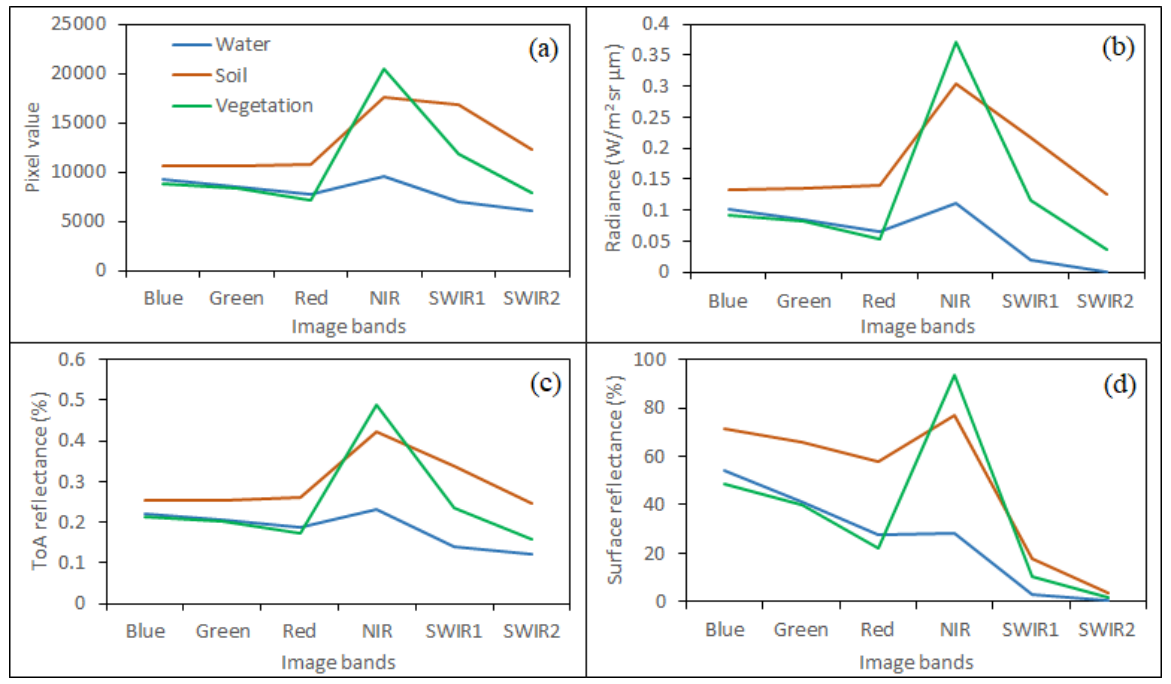

Fig. 2. Comparison of image correction results: (a) digital number, (b) at-sensor radiance, (c) atsensor reflectance, and (d) at-surface reflectance.

Three main land cover objects (water, soil, vegetation) were selected and plotted into the scatter graphs to enable visual examination of the changes. These object patterns resemble the standard spectral reflectance pattern commonly available in the literatures. From the graphs in Fig. 2 we can only examine the curve pattern change, and not the quantitative value difference between correction level because they have different units.

\subsection{Land cover training samples}

Sampling was done by visual interpretation for each land cover class in each level of image correction, so that there was a single set of samples for single year of observation. The sample selection also supported by field visit on July 2019. A total of 484 samples were collected purposively from Landsat 8 OLI imagery to represent water body (137), bare land (47), built-up (116), mangroves (71), and inland vegetation (113). The spatial distribution of land cover sample points can be seen in Fig. 3. Water body objects consist of sea water, river and fishponds; it is noticeable with dark blue objects in the image. Built-up objects are associated with urban areas in the north part of the image and villages in the coastline areas. The bare lands were mostly found surrounding the built-up areas. The mangrove objects mostly found in Perancak Estuary and some within the fishponds area with dark green colour in the image. Inland vegetation can be recognised with bright green colour and spread across the image.

We tried to keep the sample distribution as spread as possible across the image to maintain the representativeness of the targeted land cover spectral reflectance variation. The choice of target land cover class is the most dominant object of land cover in the study area. We deliberately chose a small number of land cover because this study focused more on the aspects of the effect of image correction levels to the consistency of classifications results, not on variations of land cover objects that can be mapped. 


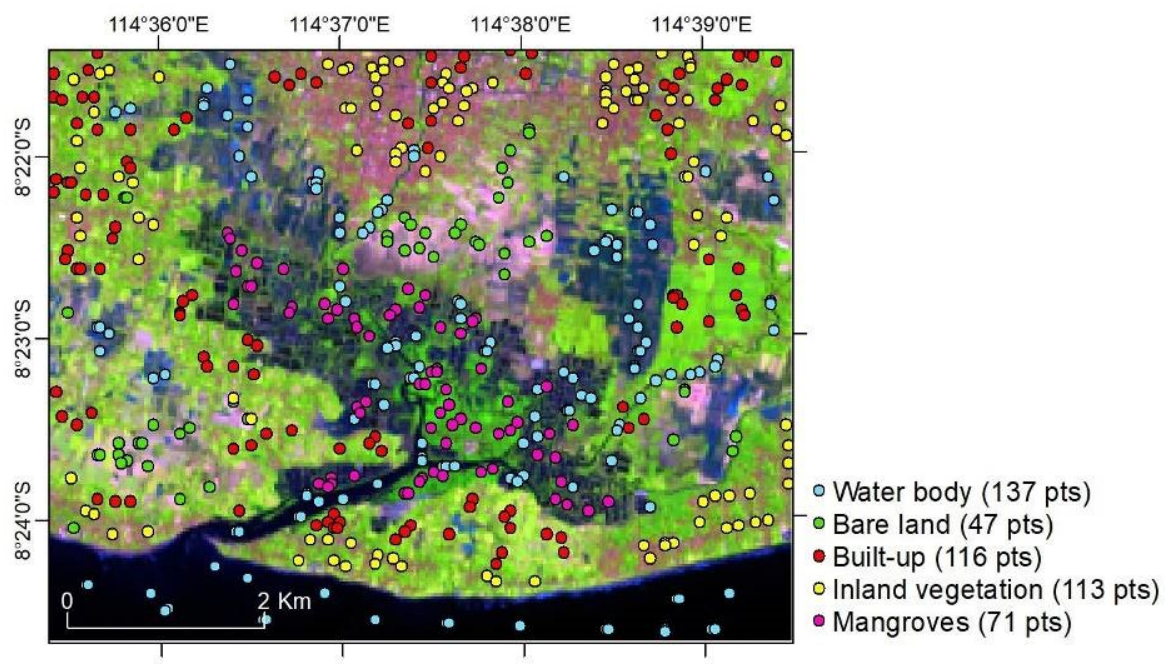

Fig. 3. Spatial distribution of land cover samples (background image Landsat 8 OLI RGB 654).

\subsection{Comparison of land cover maps}

The land cover maps were produced from applying an MLC algorithm to the Landsat 8 OLI image at four different correction levels. These land cover maps were compared and contrasted to evaluate the effect of different image correction level to the produced land cover maps. Fig. 4 shows an evidence that the level of image correction does not affect the classification result of land cover carried out. The results of the MLC classification for land cover at each level of correction show the same class extent and distribution in each image. As expected, mangroves objects are located in the middle part of the study site, where there is mangrove conservation area and many mangroves patch within the fishpond areas. Builtup areas are located in urban area in the north part of study site and in villages in the coastal areas. Bare land class mostly associated with built-up class and inland vegetation are spread across the study area. 

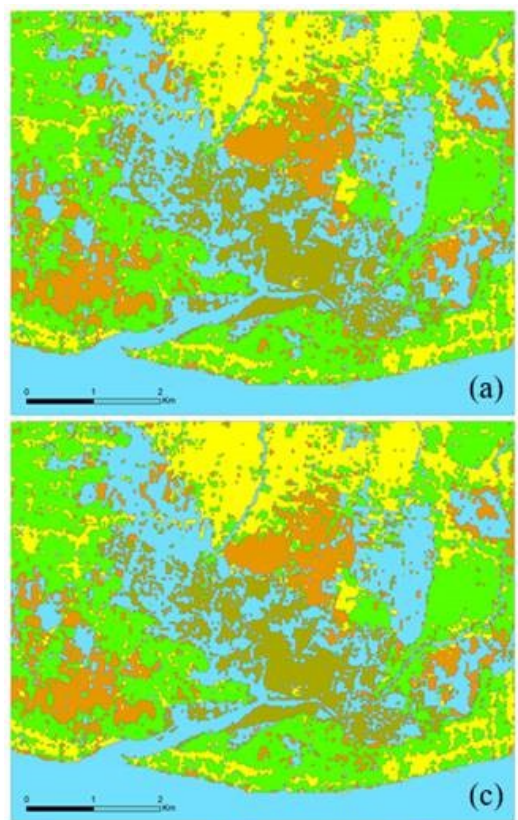

Water body $\square$ Bare land $\square$ Built-up
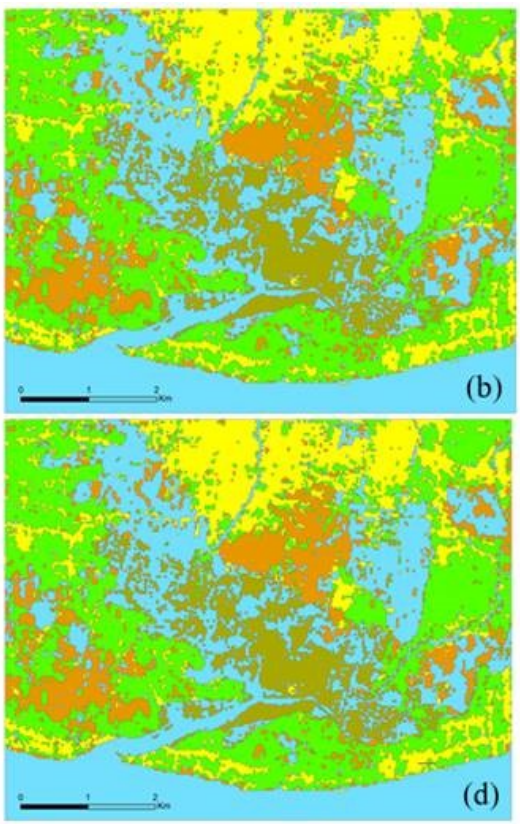

Inland vegetation $\square$ Mangroves

Fig. 4. Spatial distribution of land cover at three different years; (a) digital number, (b) at-sensor radiance, (c) at-sensor reflectance, and (d) at-surface reflectance.

MLC considers the statistical distribution of the sample pixel values relative to the image pixel values across the entire scene of observation. It assumes that the statistics for all targeted classes in each band are normally distributed. Each pixel on the image is assigned to the class that has the highest probability to be included in the targeted class member. Any changes in pixel value will not affect the statistical distribution of the sample class membership in MLC algorithm. Therefore, the value of pixels that have gone through various stages of correction does not affect the results of the MLC classification. This finding also confirmed by the comparison of the total size of land cover classes across the image correction levels (Fig. 5). In this case, all land cover classes have similar size across different image correction levels.

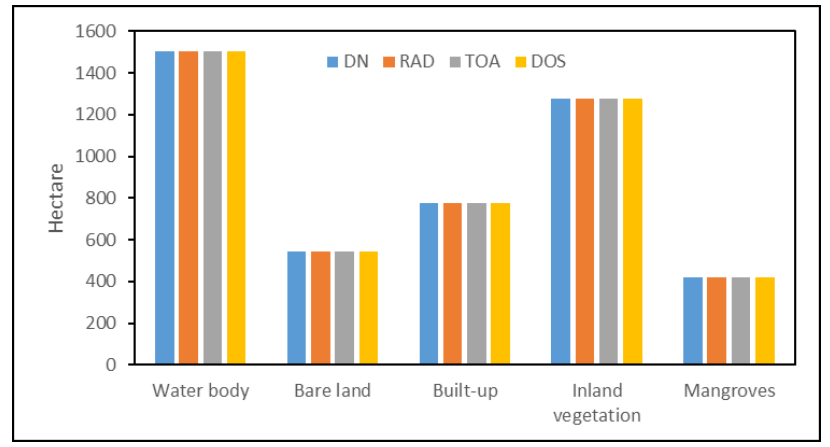

Fig. 5. Land cover size measured for each class at different image correction levels.

\section{Conclusions}


The main finding of this study shows that the level of image correction level does not affect the result of MLC-derived land cover maps. There is no different both in the land cover class distribution and size for land cover maps produced from different image correction level. This finding provides a fundamental understanding of the practical implementation of MLC in land cover maps. MLC-derived land cover map can be done on remote sensing image without performing any prior radiometric or atmospheric corrections. Future works will be considered to check the consistency of this finding across different time of acquisition, and to apply this finding for change detection purpose.

This research was funded by Independent Lecturer Research Grant (Hibah Penelitian Dosen Mandiri) from Faculty of Geography (FGE), Universitas Gadjah Mada (UGM), contract number 2056.45/UN1/FGE/KPT/SETD/2019. The authors would like to thank (1) Department of Geographic Information Science (FGE, UGM) for providing research facilities, and (2) Dian Utari, Zulfikri Isnaen, Aldo Restu Agi Prananda, and Rani Rahim Suryandari for helping during the fieldwork.

\section{References}

1. C. Kuenzer, A. Bluemel, S. Gebhardt, T.V. Quoc, S. Dech, Remote Sens-Basel 3, 878$928(2011)$

2. E.L. Gilman, J. Ellison, N.C. Duke, C. Field, Aquat Bot 89, 237-250 (2008)

3. C. Giri, B. Pengra, Z. Zhu, A. Singh, L.L. Tieszen, Estuar Coast Shelf S 73, 91-100 (2007)

4. B.W. Heumann, Prog Phys Geog 35, 87-108 (2011)

5. J.R Jensen, Introductory Digital Image Processing: A Remote Sensing Perspective (Prentice Hall, New Jersey, 2005)

6. C. Song, C.E. Woodcock, K.C. Seto, M.P. Lenney, S.A. Macomber, Remote Sens Environ 75, 230-244 (2001)

7. BROK (Balai Riset dan Observasi Kelautan), Laporan Riset Observasi dan Kajian Pemanfaatan Kawasan Konservasi Lau (BPOL, Perancak, 2004)

8. R. Rahmania, C. Proisy, O. Germain, P. Gaspar, G. Viennois, J. Prosperi, A. Andayani, B. Subki, A.R. Farhan, F. Sidik, N. Widagti, Suhardjono, Proceedings of the $20158^{\text {th }}$ International Workshop on the Analysis of Multitemporal Remote Sensing Images (Multi-Temp), 1-4 (2015)

9. Ruslisan, M. Kamal, F. Sidik, IOP Conference Series: Earth and Environmental Science, Vol 123, conference 1: The 2nd Geoplanning-International Conference on Geomatics and Planning (2018)

10. BROK (Balai Riset dan Observasi Kelautan). Laporan Riset Observasi dan Kajian Pemanfaatan Kawasan Konservasi Laut (BPOL, Perancak, 2009)

11. USGS, Landsat 8 (L8) Data Users Handbook (Department of the Interior USGS, Sioux Falls, South Dakota, 2019)

12. P.S. Chavez Jr., Remote Sens Environ 24, 459-479 (1988) 